\title{
Colaboração e open innovation: a importância da governança colaborativa para a constituição de um ecossistema de inovação aberta em um Arranjo Produtivo Local (APL)
}

\author{
Collaboration and open innovation: the importance of collaborative \\ governance for the constitution of an open innovation ecosystem in a \\ Local Productive Arrangement (APL)
}

\section{Colaboración y open innovation: la importancia de la gobernanza colaborativa para la constitución de un ecosistema de innovación abierta en un Arreglo Productivo Local (APL)}

\author{
Cátia Raquel Felden Bartz ${ }^{1}$ \\ Jéssica Casali Turcato ${ }^{1}$ \\ Jorge Oneide Sausen ${ }^{1}$ \\ Daniel Knebel Baggio ${ }^{1}$
}

Recebido em 25/07/2018; revisado e aprovado em 06/05/2019; aceito em 19/06/2019. DOI: http://dx.doi.org/10.20435/inter.v21i1.2097

\begin{abstract}
Resumo: O presente trabalho analisa a dinâmica da colaboração e da open innovation de um Arranjo Produtivo Local (APL), da Região Noroeste do Rio Grande do Sul, pela perspectiva da governança colaborativa e da formação de um ecossistema de inovação aberta. O presente estudo enquadra-se no paradigma Humanista Social, com abordagem qualitativa, e teve 22 atores entrevistados que ocupam posição estratégica na governança. A presente pesquisa analisou a Governança Colaborativa do APL, sobre a ótica de três dimensões: 1ạ dimensão: análise do processo de constituição e amadurecimento do próprio APL; 2a dimensão: compreensão dos elementos constituidores da inovação aberta; 3 a dimensão: compreensão sobre as interações estabelecidas entre os diversos atores internos e externos ao APL, representados por seus laços fortes e fracos. Conclui-se que, apesar de existir um modelo de governança colaborativa baseado na comunicação "face to face", compromisso com o processo e visão compartilhada, este não é capaz de fazer com que as empresas compartilhem informação referente à inovação, dificultando a classificação do APL como um ecossistema de inovação. Para estudos futuros, recomenda-se a ampliação da amostra, para que seja possível analisar e comparar a governança colaborativa, entre os diversos arranjos produtivos existentes.
\end{abstract} Palavras-chave: articulação coletiva; colaboração; governança colaborativa; inovação; open innovation.

Abstract: This paper analyzes the dynamics of collaboration and open innovation of a Local Productive Arrangement (APL), in the Northwest Region of Rio Grande do Sul, through the perspective of collaborative governance and the formation of an open innovation ecosystem. The present study fits the Humanist Social paradigm, with a qualitative approach, and had 22 interviewed actors who occupy a strategic position in governance. The present research analyzed the Collaborative Governance of APL, on the three dimensions perspective: 1st dimension: analysis of the process of constitution and maturation of the APL itself; 2 nd dimension: understanding the constituents of open innovation; 3rd dimension: understanding about the interactions established between the various actors internal and external to the APL, represented by their strong and weak ties. It is concluded that, although there is a collaborative governance model based on "face to face" communication, commitment to the process and shared vision, it is not capable of causing companies to share information about innovation, making it difficult to classify the APL as an ecosystem of innovation. For future studies, it is recommended to expand the sample, so that it is possible to analyze and compare the collaborative governance among the various productive arrangements.

Keywords: collective articulation; collaboration; collaborative governance; innovation; open innovation.

Resumen: El presente trabajo analiza la dinámica de la colaboración y la open innovation de un Arreglo Productivo Local (APL), de la Región Noroeste de Rio Grande do Sul, por la perspectiva de la gobernanza colaborativa y de la formación de un ecosistema de innovación abierta. El presente estudio se encuadra en el paradigma Humanista Social, con abordaje cualitativo, y tuvo 22 actores entrevistados que ocupan posición

\footnotetext{
${ }^{1}$ Universidade Regional do Noroeste do Estado do Rio Grande do Sul (UNIJUÍ), ljuí, Rio Grande do Sul, Brasil.
} 
estratégica en la gobernanza. La presente investigación analizó la Gobernanza Colaborativa del APL, sobre la óptica de tres dimensiones: 1a dimensión: análisis del proceso de constitución y maduración del propio APL; 2a dimensión: comprensión de los elementos constitutivos de la innovación abierta; 3a dimensión: comprensión sobre las interacciones establecidas entre los diversos actores internos y externos al APL, representados por sus lazos fuertes y débiles. Se concluye que, a pesar de existir un modelo de gobernanza colaborativa basado en la comunicación "cara a cara", compromiso con el proceso y visión compartida, éste no es capaz de hacer que las empresas compartan información referente a la innovación, dificultando la clasificación del producto APL como un ecosistema de innovación. Para estudios futuros, se recomienda la ampliación de la muestra, para que sea posible analizar y comparar la gobernanza colaborativa, entre los diversos arreglos productivos existentes.

Palabras clave: articulación colectiva; colaboración; gobernanza colaborativa; innovación; open innovation.

\section{INTRODUÇÃO}

Os avanços tecnológicos tiveram grandes impactos sobre o modo como as empresas se organizam, surgindo, assim, novos modelos de negócios, com uma visão ampliada do real significado do termo "colaboração" entre os stakeholders. Neste cenário, a temática da governança assumiu um lugar de destaque no debate empresarial e nas pesquisas acadêmicas. Originária dos trabalhos seminais de Coase (1937), Williamson (1996) e Jensen e Meckling (1976), a governança construiu suas bases em um contexto organizacional de incerteza, conflito de interesses, assimetria informacional e contratos incompletos. A governança ganhou ainda mais complexidade quando as organizações ou territórios passaram a buscar, por uma ação coletiva e articulada, melhorar seus desempenhos individuais. Neste contexto, os potenciais conflitos possuem as mesmas características, mas se agregam dificuldades pelo fato do comportamento oportunista de atores e organizações e também pelos diferentes fatores que gerarão competitividade nas distintas organizações deste coletivo.

Nessa conjuntura, emerge não necessariamente uma nova forma de governança, mas um novo estilo de conduzi-la que permite, pelo aprofundamento de relações dialógicas (HABERMAS, 1987), a construção de convergências que possam subsistir aos múltiplos interesses envolvidos. A ideia é gerar um reposicionamento, movendo-se de uma perspectiva de adversários para uma de parceria, que, mesmo possuindo particularidades, consegue vislumbrar pontos comuns que podem ser conduzidos de modo coletivo e articulados. A governança colaborativa, como se tornou conhecida, reúne as partes interessadas (multiatores) em fóruns coletivos para se empenharem na tomada de decisões orientadas para o consenso.

O modelo de gestão organizacional, baseado nos preceitos de governança colaborativa, é uma perspectiva contemporânea de gestão de interesses e tem conseguido posicionar-se como um meio de solucionar problemas complexos (AGRANOFF, 2005; BODIN, 2017) pela gestão e elaboração de políticas através de decisões consensuais (ANSELL; GASH, 2007; EMERSON; NABATCHI; BALOGH, 2012). A GC também ganhou espaço em função de falhas de sistemas de governança anteriores, como resposta à lentidão desses sistemas e ao alto valor em termos de custo de oportunidade de suas organizações, bem como a politização da regulamentação (ANSELL; GASH, 2007).

$\mathrm{Na}$ atual circunstância organizacional, marcada pela abertura e mobilidade, em que a capacidade de inovação é fator determinante para a sobrevivência de praticamente todas as organizações, debater as estratégias de solidificar e ampliar relações é uma pauta obrigatória. Autores como Innes e Booher (1999), Adner (2006), Lane, Koka e Pathak (2006), Ansell e Gash 
(2007), Tidd, Bressat e Pavitt (2015), Guerra, Tondolo e Camargo (2016) e Bodin (2017) entendem que a governança colaborativa é essencial para a constituição de um ecossistema de inovação. Um ecossistema de inovação é formado por uma cadeia de arranjos colaborativos (ADNER, 2006), que formam um processo de aprendizagem, como apontam Nonaka e Takeuchi (1997). Assim, a colaboração é um meio para potencializar a geração de conhecimento pela aprendizagem social, proveniente da interação entre distintos atores, que integram as ideias dos diferentes sistemas e assim difundem conhecimento e as melhores práticas entre eles (BODIN, 2017).

Desse modo, esta pesquisa propõe uma investigação em torno da constituição de um modelo de governança colaborativa, na tentativa de compreender a dinâmica de colaboração de um Arranjo Produtivo Local (APL), metalmecânico da Região Noroeste do Estado do Rio Grande do Sul, na perspectiva de formação de um ecossistema de open innovation (inovação aberta). Na primeira parte do artigo, são apresentados os conceitos de inovação e ecossistemas de inovação. A discussão sobre os ecossistemas de inovação conduz diretamente ao conceito de inovação aberta, temática desta pesquisa. Na sequência da elaboração dos constructos do referencial teórico, adentra-se aos conceitos de governança colaborativa, apresentando os principais autores que discutem o tema e também os autores que darão embasamento ao constructo metodológico desta pesquisa, Ansell e Gash (2007), Silva e Bignetti (2012) e Granovetter (1983; 1985). Na sequência, segunda parte do artigo, é apresentada a metodologia desta investigação científica, que, de acordo com Burrel e Morgan (1979), enquadra-se no paradigma Humanista Social. Na terceira parte, apresentam-se os resultados e discussões, realizando-se uma análise detalhada, com os principais pensadores do tema abordado; e, por último, são apresentadas as considerações finais desta pesquisa.

\section{INOVAÇÃO E OS ECOSSISTEMAS DE INOVAÇÃO}

A literatura sobre inovação e colaboração ganhou nova interpretação com o artigo de James Moore, de 1993, que apresentou uma metáfora para esta competição econômica, extraída de estudos sobre os sistemas biológicos e sociais, tal como ecossistema. Para Moore (1993), as empresas deveriam ser consideradas não como unidades de uma única indústria, mas como uma parte de um ecossistema de negócios, que envolve uma série de indústrias. Neste sentido, as firmas evoluem conjuntamente ao redor de uma inovação, produzindo de forma competitiva, mas também colaborativa, com o objetivo de elaborar novos produtos que satisfaçam o mercado, através de um ecossistema de inovação.

A analogia de ecossistema biológico aplicada ao ambiente empresarial teve êxito ao explorar o caráter de interdependência (IANSISTI; LEVIEN, 2004) e coevolução (MOORE, 1993) dos atores que o compõem. Nesta conjuntura de inovação, esses aspectos se tornam ainda mais importantes, pois nenhuma organização, independentemente do seu tamanho e poder econômico, possui todos os conhecimentos necessários para controlar o sistema (MOORE, 1993). Além disso, pelo fato de a inovação estar imersa em incertezas, as grandes empresas costumam ter dificuldades para se adaptarem às mudanças exigidas, por isso, preferem esperar até que uma tecnologia amadureça para depois incorporá-la (LUBIK et al., 2013).

No caso das pequenas empresas, essas precisam arriscar, pois posteriormente não conseguirão alcançar a inovação (ADNER, 2006) e estão dependentes de parceiros para ter acesso a recursos dos quais não possuem (LUBIK et al., 2013). Por outro lado, deve-se considerar ainda 
que há uma clara necessidade de capturar oportunidades externamente e que políticas podem estimular essa atividade, independentemente do porte da empresa (FISHER; ZAYAS, 2012). Neste sentido, a abordagem de ecossistema menciona uma dinâmica denominada colaboração, em que atores rivais aceitam colaborar para obterem algum benefício, embora sejam competidores entre si (BENGTSSON; KOCK, 2000). Esta perspectiva faz uma conexão com o arcabouço dos clusters industriais, arranjos produtivos e parques tecnológicos, em função das economias de escala e de escopo possíveis com a adoção de práticas colaborativas dentro de um mesmo ambiente competitivo (MALMBERG; MASKELL, 2001).

Para Audy e Piqué (2016) e Bodin (2017), os ecossistemas são constituídos por um conjunto de organizações, mecanismos e relações complexas, os quais necessitam de estímulos, que abrangem escalas geográficas e temporais tipicamente não alinhadas, tornando a gestão desse ecossistema desafiadora, devido ao elevado número de atores e interesses diversos (BODIN, 2017). Estes ambientes remetem à composição de um ambiente difuso, com uma multiplicidade de capacidades, em que diferentes instituições compartilham elementos comuns, ferramentas e objetivos, para aumentar o potencial próprio e a melhora da qualidade de vida da população com os serviços entregues (AUDY; PIQUÉ, 2016; AUDY, 2017).

Por fim, as características de estabilidade institucional reportam-se à importância de que a coordenação, legitimidade, confiança e mecanismos de governança têm para transparecer estabilidade ao ecossistema (RUSSEL, 2011; IKENAMI, 2016; BODIN, 2017). Essas últimas são peculiaridades vitais para a criação, desenvolvimento, modelagem da capacidade e manutenção do ecossistema, conforme mencionam os autores. De acordo com Aranha (2016), os ecossistemas de inovação permitem que as empresas otimizem seus processos de produção e distribuição, mas, além disso, desenvolvem a criação de novos produtos, serviços e processos, fenômeno chamado de open innovation. Neste conceito, as empresas se comunicam com ecossistemas, como universidades, governo, fornecedores e clientes, com o intuito de criar novos produtos, serviços ou processos inovadores, dentro de um contexto de colaboração.

\subsection{Governança e colaboração}

O conceito de governança emerge com mais contundência na transição para o novo século, associado a mudanças estruturais na sociedade, reforma administrativa e reformulação do papel do Estado, reforço da democracia participativa e descentralização nos processos (GRAY, 1989). A governança, em termos gerais, refere-se ao ato de governar as relações interorganizacionais em um contexto de ação coletiva pela articulação de normas e regras conjuntamente determinadas e projetadas para regular o comportamento individual em um contexto de grupo (OSTROM, 1990).

A forma de organizar a governança em ambientes onde se relacionam interorganizacionalmente distintos atores é determinante para o aumento da interdependência entre eles e está relacionada à coordenação e ao controle das ações e dos projetos, a fim de desenvolver e especializar seus membros, promovendo a produção de conhecimento compartilhado e estimulando a cooperação e inovação (AMORIM; MOREIRA; IPIRANGA, 2004).

Embora as hierarquias e os mercados continuem a desempenhar um papel crucial na regulação da sociedade e da economia, bem como na prestação de serviços públicos e privados, as formas colaborativas de governança estão proliferando, alimentadas pela complexidade institucional e pela fragmentação política, impulsionadas pelo reconhecimento de que nenhum 
ator tem o conhecimento ou os recursos para resolver sozinho problemas sociais complexos (KOOIMAN, 1993). Assim, a governança colaborativa é frequentemente desenvolvida quando as demandas por ação não estão sendo atendidas pelas jurisdições institucionais existentes ou, pelo menos, unilateralmente por uma única jurisdição (ANSELL; TORFING, 2015).

As concepções em torno de um modelo de governança colaborativa estão relacionadas ao desenvolvimento da governança territorial. Assim como a governança colaborativa, a governança territorial demonstra um cenário de transição da governança da ótica econômica para a dimensão da ciência política e da administração em uma gestão mais inclusiva e corresponsável dos assuntos públicos, em contraste aos modelos tributários e burocráticos tradicionais (DASÍ, 2008).

Para Dasí (2008), o Estado e os vários atores da sociedade assumem novas responsabilidades na tomada de decisões políticas, a partir de um sistema de relações mais complexas que inclui novos atores externos na arena política. A governança, nesse sentido, representa um modelo alternativo de gestão dos assuntos públicos, o surgimento e a implementação de formas de planejamento e gestão da dinâmica territorial inovadora e compartilhada. Sob esse aspecto, a governança surge em uma perspectiva que coloca "em xeque" a relação do Estado com outras organizações externas, privadas ou associativas (FERRÃO, 2010).

Esse modelo de governança territorial que emerge caracteriza-se pela relação, negociação e construção de consenso, sustentada por uma multiplicidade de atores que compartilham alguns objetivos e concordam com uma visão compartilhada para o futuro do território entre atores de diferentes níveis, públicos, privados, do terceiro setor etc. (DASÍ, 2008). A governança colaborativa congrega essas características sob uma visão proeminentemente colaborativa, em que os diversos atores se envolvem em um processo de tomada de decisão coletiva, formal, consensual e deliberativa (ANSELL; GASH, 2007) para estratégias de planejamento, regulamentação, formulação de políticas e gestão pública, que coordene e integre as metas e os interesses de várias partes envolvidas (ANSELL, 2012). Ambas as perspectivas utilizam-se de metodologias mais descentralizadas de mobilização, diálogo, conciliação de interesse e decisão, com o intuito de garantir a representatividade da diversidade e complexidade da sociedade moderna (FERRÃO, 2010).

A adoção da colaboração cria a perspectiva de um aumento da qualidade da solução, com uma abordagem mais abrangente do problema, diversificação da capacidade de respostas, minimização do risco de impasse, consideração mais equitativa dos interesses dos atores no processo e sentimento de inclusão na solução de um contingente mais abrangente de atores sociais (GRAY, 1989). Nesse contexto, Ansell e Gash (2007) propuseram um modelo de governança colaborativa baseado na crescente confiança entre os atores e na consolidação de um comportamento mais cooperativo, fundamentado no diálogo. As etapas deste processo compreendem: comunicação "face to face" (diálogo presencial entre as partes interessadas em um processo orientado por consenso, identificando oportunidades de ganhos mútuos), construção da confiança (processo colaborativo não é meramente sobre negociação, mas também sobre a construção de confiança entre as partes interessadas), compromisso com o processo (o desenho do processo decisório nos mecanismos de governança colaborativa é fundamental para a construção da confiança) e visão compartilhada (as partes interessadas devem desenvolver uma compreensão compartilhada do que eles podem alcançar coletivamente juntos).

Para Innes e Booher (1999), a governança colaborativa é essencial para a sustentabilidade dos ecossistemas de inovação, pois estimula a formação de capital intelectual (recursos de conhecimento), capital social (credibilidade e compreensão social, construídas pela interação 
pessoal) e capital político (capacidade de agir coletivamente para desenvolver qualidades locais e captar recursos e a atenção externa). Para os autores, a base de um ecossistema de inovação e aprendizagem está no modelo de governança colaborativa.

Tidd, Bessant e Pavitt (2015) ressaltam que existem diferentes graus de novidade no processo de inovação, que vão desde melhorias incrementais até mudanças realmente radicais, que transformam a maneira como são vistas ou utilizadas as coisas. Para Mazzuco e Teixeira (2017), as inovações incrementais são aquelas que acontecem de forma gradativa, que já fazem parte de melhorias existentes, enquanto inovações radicais são aquelas que mudam completamente os conceitos, resultando em produtos e processos novos que geralmente possuem um grau mais elevado de risco. Tidd, Bessant e Pavitt (2015) analisam que, à medida que a inovação se torna mais complexa, as redes têm de envolver um número crescente de participantes, muitos dos quais se encontram fora da empresa, ampliando a rede de participantes do ecossistema proporcionalmente ao ritmo da inovação. Nesse sentido, o modelo de governança colaborativa deverá internalizar o conceito de inovação aberta.

Pesquisadores como Ballon, Pierson e Delaeras (2005), Adner e Kapoor (2010) e Bodin (2017) sugerem que a organização, coordenação e o gerenciamento de atividades de open innovation sejam congruentes com um processo decisório pautado na governança colaborativa. Com o propósito de introduzir a open innovation, prática recorrente no setor privado, para os ecossistemas de inovação, surgem os chamados "intermediários da inovação" (DUTILLEUL; BIRRER; MENSINK, 2010).

A governança colaborativa propicia o compartilhamento de informações, facilita a reunião e integração de recursos e capacidades complementares de diferentes organizações, como explica Edelenbos (2005) e Suzigan, Garcia e Furtado (2007), proporcionando acesso a uma maior quantidade de recursos para a inovação, tornando possível às organizações que colaboram a obtenção de ganhos que não seriam capazes de obter individualmente (POWELL, 1998). Esta visão de ganho coletivo também está presente no entendimento de Filippim e Rosseto (2008), sobre a importância dos APLs para a economia local, pois, de acordo com os autores, as empresas que compõem um arranjo conseguem usufruir de benefícios que dificilmente conseguiriam sozinhas. Percebe-se de imediato que o conceito de open innovation de Powell (1998) está sincronizado com o entendimento de Filippim e Rosseto (2008) sobre a importância da governança colaborativa dos APLs.

Granovetter $(1983 ; 1985)$ apresenta a metáfora dos laços fortes e laços fracos como pressupostos fundamentais para a disseminação da inovação aberta, nos modelos de governança colaborativa para arranjos produtivos, clusters e aglomerados de empresas. Para Boeira e Borba (2006), Kaufman (2012) e Lima (2016), a dinâmica das relações dos laços fortes não se estende para além dos clusters, trata-se de relações com elevado nível de confiança e credibilidade local, nas relações da cadeia produtiva convencional. Já as relações existentes nos laços fracos são importantes porque conectam os atores de um determinado grupo com vários outros grupos, rompendo a configuração de "ilhas isoladas" dos clusters e assumindo a configuração de rede social (LIMA, 2016). No entendimento de Granovetter (1983; 1985), a geração da inovação aberta ocorre na dimensão das relações dos laços fracos, pelo elevado nível de compartilhamento de inovação que gera a aprendizagem na cadeia.

Corroborando com Granovetter (1983; 1985), o conceito de inovação aberta de Chesbrough (2006) refere-se a um modelo de gestão da inovação, cuja função é capturar e criar valor com 
base em oportunidades localizadas dentro e fora da cadeia. De modo complementar, segundo Chesbrough, Vanhaverbeke e West (2008), a inovação aberta envolve o uso deliberado de fluxos de conhecimentos internos e externos para acelerar a inovação interna e expandir os mercados externos com uso da inovação. A inovação aberta, nesta perspectiva, pode ocorrer como resultado do aprendizado de vários atores com conhecimentos distintos, porém complementares, que os unem em torno de uma proposta de criação de algo novo (LUNDVALL, 1992), por meio de interações de modo colaborativo e que dependem primordialmente do compartilhamento de conhecimento (DYER; NOBEOKA, 2000).

Com a intenção de explorar os limites do conceito da inovação aberta, Huizingh (2010) propõe questões relacionadas ao conteúdo de inovação aberta (o quê?), à dependência de contexto da inovação aberta (quando?) e ao processo de inovação aberta (como?). Este autor considera três aspectos de inovação aberta em relação ao seu conteúdo que podem ser compreendidos de forma a assegurar maior coerência no campo: (a) a dimensão da abertura; (b) as atividades inerentes à inovação aberta; e (c) a eficácia da inovação aberta.

O primeiro aspecto, relativo à dimensão de abertura, reconhece que a inovação aberta reflete menos uma dicotomia entre aberto versus fechado do que um contínuo com graus variados de abertura (DAHLANDER; GANN, 2010). Em relação às atividades inerentes à inovação aberta, duas perspectivas são consideradas: as atividades de entrada da inovação aberta que se referem ao uso interno do conhecimento externo e as atividades externas da inovação aberta que se referem à exploração de conhecimento interno. Quanto à eficácia da inovação aberta, esperam-se resultados intermediários, ligados ao compartilhamento de conhecimento e geração de aprendizado, e resultados diretos, voltados à ampliação do impacto ou alcance da inovação. Quanto à dependência da inovação aberta em relação ao contexto, consideram-se características tanto do contexto interno, relacionadas à demografia e a estratégias, quanto do externo, relacionadas, mais claramente, à indústria (GASSMANN, 2006).

Silva e Bignetti (2012) construíram um esquema teórico que permite a identificação de dimensões de análise da inovação aberta quanto ao seu conteúdo, à sua dependência do contexto e ao seu processo. Pelo conteúdo, as categorias contemplam: dimensões de abertura, atividades inerentes e eficácia. Quanto à dependência do contexto, são as categorias internas e externas. Por fim, quanto ao processo, as categorias são: abertura das práticas de inovação e forma com que as práticas de inovação aberta são conduzidas.

Como se observa, há uma vinculação entre processos internos e externos, que conduzem à inovação aberta. De fato, se a inovação aberta se caracteriza pelo envolvimento de atores da sociedade civil, autonomamente ou em parceria com o poder público na busca de soluções para seus problemas, a ação conjunta dos atores fornece a necessária sinergia e o essencial fluxo de conhecimentos teóricos e práticos para a obtenção de resultados duradouros (SILVA; BIGNETTI, 2012).

\section{METODOLOGIA}

De acordo com Burrel e Morgan (1979), a pesquisa enquadra-se no paradigma Humanista Social. Este paradigma está envolvido em uma visão da sociedade que prega a importância de transcender as limitações dos arranjos sociais que nos cercam e que contempla o mundo social de uma perspectiva que tende a ser nominalista, antipositivista, voluntarista e ideográfica. Os autores Burrel e Morgan (1979) descrevem que esse paradigma possui a visão de uma sociedade 
contemporânea caracterizada por conflitos fundamentais que convergem em mudanças radicais - isso pode ocorrer através de crises políticas ou crises econômicas.

A pesquisa específica, aqui relatada, é um estudo de caso (YIN, 2001) qualitativo; referente aos procedimentos metodológicos, utilizou-se de entrevista semiestruturada, pesquisa documental e pesquisa bibliográfica. Destaca-se que as entrevistas foram feitas com o consentimento dos entrevistados e, como o conteúdo envolveu percepções a respeito de aspectos relacionados a ações e estratégias de governança, ou seja, aspectos administrativos, entendeu-se desnecessário passar pelo comitê de ética em pesquisa da universidade, uma vez que não envolveu experimentos e/ou abordagem de cunho psicológico com seres humanos.

Depois destas definições metodológicas, iniciou-se a busca pela construção do referencial teórico. A construção do referencial teórico ocorreu por meio da consulta à base de dados Scopus e Science Direct, utilizando as palavras-chave: governança colaborativa, arranjo produtivo local, ecossistemas de inovação e inovação aberta. Após a introdução das palavras-chave, foi realizado um refinamento por área de pesquisa, e apenas os artigos da área de gestão e economia foram selecionados.

A construção do questionário semiestruturado englobou a análise de três dimensões, cada uma delas desdobrada em um conjunto de variáveis: 1a dimensão: análise do processo de constituição e amadurecimento do próprio APL; 2a dimensão: compreensão dos elementos constituidores da inovação aberta; 3 a dimensão: compreensão sobre as interações estabelecidas entre os diversos atores internos e externos ao APL, representados por seus laços fortes e fracos.

As variáveis consideradas na análise da primeira dimensão "análise do processo de constituição e amadurecimento do próprio APL" foram definidas por Ansell e Gash (2007): a) Comunicação "face to face", b) confiança, c) compromisso com o processo e d) visão compartilhada de futuro. Estas variáveis foram analisadas em uma perspectiva histórica longitudinal (PETTIGREW; FERLIE; McKEE, 1992), em função do fato de que o APL foi se modificando e, à medida que adquiria maior maturidade, alterava-se igualmente o modo como cada uma destas variáveis era percebida e gerenciada.

Após a aplicação das variáveis presentes na primeira dimensão, a pesquisa buscou, também a partir da percepção dos atores que integraram o APL, compreender quais foram os elementos constituidores da inovação aberta. Nesta segunda dimensão, as variáveis pesquisadas foram propostas pelos estudos de Silva e Bignetti (2012): a) conteúdo da inovação, b) Dependência do contexto e c) análise do processo.

A terceira dimensão de análise envolveu o aprofundamento das variáveis que constituem os laços fortes e laços fracos propostos por Granovetter (1983; 1985). Pela proposição do autor, foi considerado que laços fortes são as relações existentes dentro da estrutura original do APL (empresas, instituições de ensino, organizações estatais de apoio à produtividade empresarial, associações de classes, sindicatos, gestão pública municipal) e laços fracos decorrem de todas as relações com organizações que não pertencem ao APL. Este último aspecto é fundamental, pois os processos de inovação não possuem uma origem exclusivamente interna ao sistema em análise, mas envolvem o grau de interação interorganizacional também com agentes externos. No referencial teórico do presente artigo, encontram-se, de forma detalhada, as dimensões de análises propostas por Ansell e Gash (2007), Silva e Bignetti (2012) e Granovetter (1983; 1985). Os autores utilizados na construção dos questionários semiestruturados também serviram à construção da análise e discussão dos resultados. 
Atualmente, existem 36 APLs registrados no Rio Grande do Sul, mas apenas 20 deles são apoiados pelo Governo do Estado, abrangendo 19 regiões do Rio Grande do Sul. Nesse conjunto, estão seis APLs da agroindústria familiar, três ligados à nova economia, dois de tecnologia da informação e os demais da economia tradicional (agronegócio e indústria tradicional). Destacase que a caracterização dos APLs é realizada de acordo com as suas atividades econômicas, conforme a Classificação Nacional de Atividade Econômica (CNAEs).

Figura 1 - Mapa da Localização dos APLs do Rio Grande do Sul

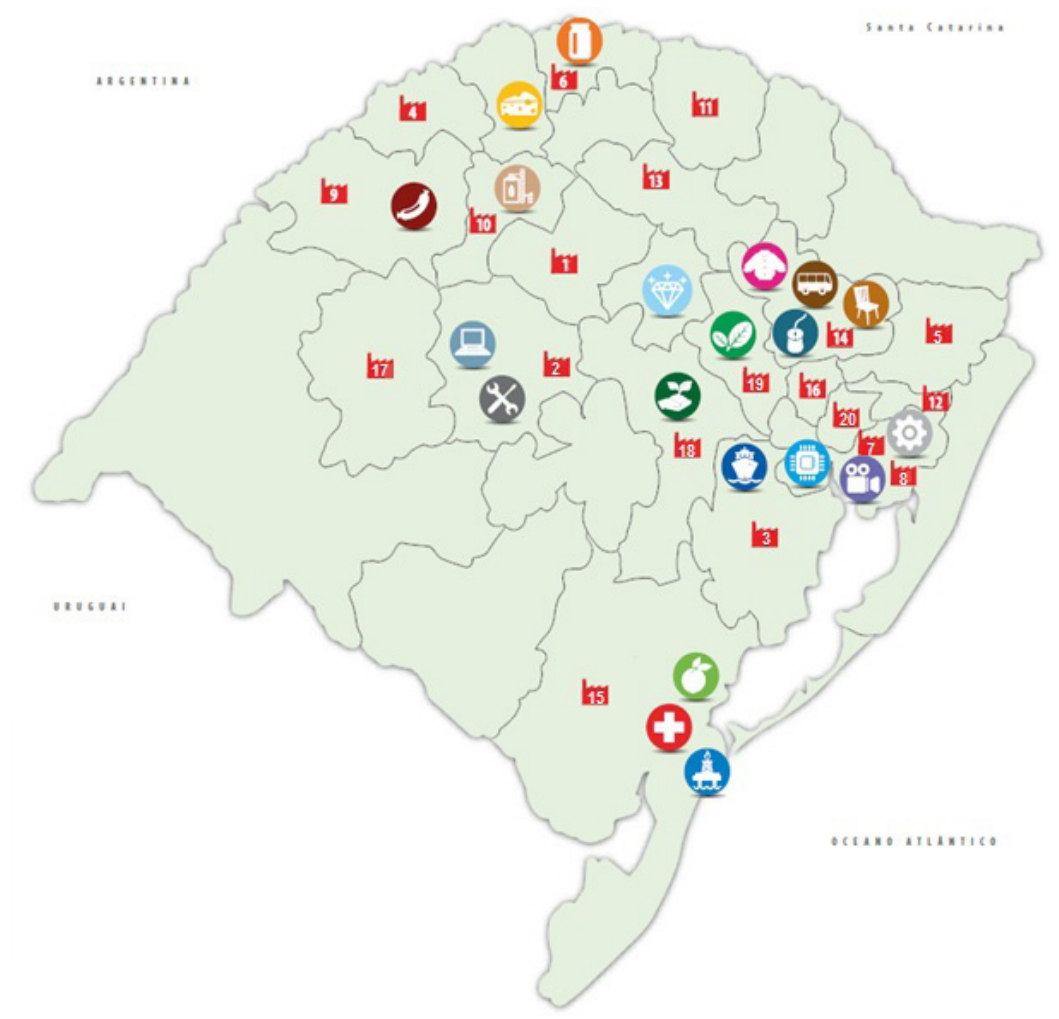

Fonte: Fonte: Secretaria de Desenvolvimento Econômico e Turismo do Estado do Rio Grande do Sul (SEDETUR, 2018).

No que se refere à amostra da pesquisa, a unidade de análise contempla um Arranjo Produtivo Local (APL) localizado na Região Noroeste do Rio Grande do Sul, aqui denominado apenas como APL, para mais liberdade de análise e interpretação dos dados. O APL é composto por 58 empresas, que atuam nos seguintes segmentos: eletroeletrônico, metalúrgico, serviços e termoplásticos. De acordo com o Ministério do Desenvolvimento, Indústria e Comércio Exterior (BRASIL, s.d.), atualmente as cidades que integram o APL possuem 56.619 habitantes, sendo que as empresas integrantes deste APL empregam 3.997 colaboradores, possuindo uma renda per capita de $R \$ 45.258,00$.

No primeiro momento, foram entrevistados os responsáveis pela governança do APL, entidades públicas e privadas, representantes dos empresários, instituições de ensino superior, gestores de incubadoras, gestores de redes de inovação e gestores de instituições de ensino, totalizando 22 entrevistados. Todos os entrevistados ocupam posição estratégica na governança do $A P L$, com poder consultivo e deliberativo. As entrevistas foram realizadas de forma presencial, por telefone e videoconferência, no período de outubro de 2017 a fevereiro de 2018. Na segunda 
etapa, foi adicionada a análise secundária dos dados, ou seja, análise documental, disponível em documentos físicos, digitalizados e websites. Evidencia-se que a pesquisa documental realizada em contratos, convênios e atas de fundações foi de extrema relevância para a compreensão da estrutura de governança do APL.

\section{ANÁLISE E DISCUSSÃO DOS RESULTADOS}

Cassiolato, Lastres e Maciel (2003) apontam que fatores como interação, cooperação e aprendizagem, característicos dos APLs quando bem articulados, são capazes de potencializar a capacidade inovativa endógena, gerando competitividade e desenvolvimento local. Esta pesquisa também encontra justificativa em Puga (2003), que relaciona o desempenho dos APLs com a sua estrutura de governança, posto que, para este autor, a participação do governo local, iniciativa privada, sociedade civil, associações comerciais, centros de pesquisa, ONGs e incubadoras é fundamental para o desenvolvimento inovativo dos APLS. Nesse sentido, pode-se compreender que, diante dos resultados obtidos, a estrutura de governança do APL em análise possui cooperação com os "intermediários da inovação", conceito apresentado por Dutilleul, Birrer e Mensink (2010), constituindo uma dinâmica de governança colaborativa.

Os APLs surgiram com o apoio e a coordenação do Sebrae/RS no ano de 2003, dando início à sensibilização e à busca da participação dos empresários. O processo inicial de construção do modelo de governança colaborativa deu-se pela formação dos mesmos atores: empresas privadas, pequenas, médias e grandes empresas, as últimas conhecidas também como "empresas-âncoras". Além das empresas, o processo inicial de governança, capitaneado pelo SEBRAE, contou com a colaboração do SENAI, Associações Comerciais (ACI), Instituições de Ensino Superior, Sindicatos, Gestão Pública Municipal e Agência Gaúcha de Desenvolvimento e Promoção do Investimento (AGDI), constituindo, nesse primeiro momento, um modelo de governança territorial (DASÍ, 2008; FERRÃO, 2010) que, a partir da articulação de distintos atores, de modo descentralizado, e de um novo papel do Estado com a sociedade, fomentou a formação de um arranjo colaborativo. A conjuntura dos APLs é uma perspectiva promissora, visto que Ferrão (2010) propõe uma crítica diante das habituais políticas de natureza intrinsicamente territorial, que demonstram os efeitos negativos da desdiferenciação de políticas resultante da crescente ambição e perspectiva particular atribuída para cada uma delas.

As entrevistas revelaram que, no APL analisado, todas as etapas de implementação da governança foram concluídas, e a construção da confiança e a visão de futuro compartilhada foram fundamental. De acordo com o representante da classe dos empresários, o diálogo "face to face" foi um processo difícil inicialmente, pois havia muitos interesses particulares em jogo e objetivos distintos, mas este conflito inicial foi fundamental para que o processo de construção da confiança fosse estabelecido, uma vez que cada ator pode dialogar e exercitar sua capacidade de ceder e confiar na decisão majoritária do grupo. Ansell e Gash (2007) apontam que o diálogo face a face é mais do que meramente o meio de negociação, é o cerne do processo de quebrar estereótipos e outras barreiras à comunicação que impedem a exploração de ganhos mútuos em primeiro lugar; o diálogo claro e transparente é o passo inicial para a construção da confiança nas redes de colaboração. O que se torna evidente, neste estudo de caso, é que a construção da confiança é um processo longo e complexo, que exige comprometimento de longo prazo para alcançar resultados realmente colaborativos. 
Quando discutida pela perspectiva da governança territorial, questões relacionadas à colaboração também despontam, pois o funcionamento promissor das parcerias, sobretudo se envolverem um alto grau de complexidade, carece de confiança, reciprocidade e coevolução entre os atores, o que exige tempo e amadurecimento das relações de colaboração, sendo que, diante de problemas de cooperação pré-existentes, esses processos se tornam mais decisivos e lentos (FERRÃO, 2010). Esses fatores foram diagnosticados nas relações do APL, revelando que, além da alta complexidade das relações, há modificações nos resultados em relação a questões como a confiança, constatando que se trata de um processo de construção contínuo, o qual não se esgota e é, primordialmente, estabelecido entre os atores, e não entre as empresas.

O compromisso com as etapas do processo proposto pelo modelo de governança implantado teve as suas sete fases concluídas pelo APL na data de finalização deste estudo. No ano de 2007, ocorreu um fato marcante, a instituição coordenadora na constituição do APL, uma agência estatal, sofreu uma forte restrição orçamentária, não conseguindo dar continuidade ao apoio financeiro dos projetos APL, principalmente em nível federal, que era uma de suas grandes possibilidades até então. Contudo, mesmo diante desta crise financeira no Sistema " $\mathrm{S}$ ", os membros do APL continuaram seu processo de implementação e consolidação. Durante este processo, o comprometimento com o futuro do APL e a união do grupo foram fatores fundamentais para a continuidade do projeto, conforme relatado nas entrevistas efetuadas. Segundo Ferrão (2010), quando se discute governança territorial, deve-se ter por base o esforço colaborativo do grupo de atores, e não iniciativas isoladas, como ocorre neste estudo de caso.

Estes resultados vão ao encontro do que já apontou Bodin (2017), o qual diz que o processo de tomada de decisão coletivo que envolve um grupo ampliado de partes interessadas implica em responsabilidade compartilhada no processo, assim, todos são responsáveis pelos ganhos e pelas perdas. Esta responsabilidade exige que as partes interessadas vejam seu relacionamento com outras partes interessadas em uma nova luz, na qual compartilhem a responsabilidade com seus interlocutores de modo a buscar situações de consenso. Este consenso foi levantado pelos participantes da pesquisa como a principal dificuldade à sua consolidação. O consenso é o fator que dificulta a ampliação da visão de futuro compartilhado, porém os participantes também percebem que houve avanços neste ponto e que o grupo amadureceu em seus processos dialógicos (TENÓRIO, 2013; HABERMAS, 1987). Para os membros do APL, esta busca de consenso também significa que as pessoas podem expressar sua visão sem receios e isto fortalece a união do grupo.

Nesta linha, quando Granovetter (1985) discute o impacto dos laços fortes e fracos na dinâmica dos grupos sociais, também destaca a confiança existente no grupo e a importância da cooperação na produção do consenso. Um destes pontos de consenso envolveu a elaboração de uma ampla pesquisa de mercado sobre os principais clientes das empresas pertencentes ao APL. Após esta definição, foi elaborado um projeto a fim de captar recursos para a execução de uma ampla e consistente pesquisa de mercado. A pesquisa foi realizada e, com base nos dados, foram elaboradas estratégias com o setor público e privado, que gerou diversos benefícios para as empresas pertencentes ao APL, como: capacitação de mão de obra, incentivo à participação em feiras e eventos, financiamento para empresas com subsídios e políticas de financiamento para que os clientes pudessem adquirir os produtos com incentivos fiscais, utilizando créditos tributários.

Nas duas circunstâncias analisadas anteriormente, como a ruptura do recurso financeiro ao SEBRAE e a contratação de pesquisa de mercado especializada, evidencia-se a visão de futuro 
compartilhada no APL, o que fortalece os pilares da governança colaborativa que está em processo de construção. O fortalecimento do processo de governança colaborátiva ocorre diante de pequenas conquistas, que são estímulos para uma colaboração bem-sucedida. Essas pequenas vitórias podem voltar ao processo colaborativo, incentivando um ciclo virtuoso de construção e compromisso de confiança (VANGEN; HUXHAM, 2003).

$\mathrm{Na}$ análise da open innovation, percebe-se que a inovação disruptiva ocorre essencialmente nas empresas denominadas "âncoras", pois este tipo de inovação demanda significativos investimentos financeiros. Neste ponto de análise da open innovation, o discurso dos atores remodela-se, e percebe-se que a comunicação e a confiança não se apresentam como pontos fortes. Ao relacionar a análise da open innovation com os "laços fortes e laços fracos" de Granovetter (1983; 1985), percebe-se que esta é bastante tênue. As empresas de grande porte possuem maior facilidade na busca de recursos financeiros que fomentem a sua inovação disruptiva, uma vez que os laços criados a partir de suas relações com o mercado são mais diversificados, tais como os laços fracos (GRANOVETTER, 1983; 1985). As pequenas e médias empresas cabem à inovação processual ou incremental. De acordo com um empresário local, o fato de sua empresa fornecer peças e serviços para uma empresa-âncora gera inovação em seu processo produtivo, pois os controles e procedimentos exigidos, alinhados com a constante necessidade de redução de custos, forçam-no a se adaptar e a inovar. Nesta fala do empresário, percebe-se claramente que a open innovation não está presente no modelo de governança do APL, mas sim na relação bilateral "cliente e fornecedor" ou "fornecedor e mercado".

Neste sentido, pela análise de Huizingh (2010) sobre o conteúdo da inovação, entende-se que as empresas ainda não compartilham sua estratégia de inovação no APL, dificultando a aprendizagem coletiva e tornando difícil a classificação do APL como um ecossistema de inovação. A inovação ocorre muito mais pela adaptação às exigências do mercado do que por um processo proativo de desenvolvimento. Em relação ao conteúdo, a) a dimensão da abertura; b) as atividades inerentes à inovação aberta; e c) a eficácia da open innovation, infere-se que estes aspectos ocorrem na perspectiva dos laços fracos. Na análise da dimensão da abertura, as empresas conseguem cooperar na busca de alternativas para a resolução de problemas de inovação que são gerais a todos os membros do APL, como na qualificação da mão de obra e pesquisas de novos mercados. Já as atividades inerentes a open innovation são adaptativas e, na maioria das empresas, concentram-se nos laços fortes, o que implica que a aprendizagem no APL ocorre pela adaptação. Os atores que lideram o processo de governança são em sua maioria gestores das pequenas e médias empresas; nesse sentido, a governança do APL é fortemente orientada para um modelo de inovação incremental.

$\mathrm{Na}$ análise das atividades inerentes à open innovation, consegue-se perceber uma atividade que pode ser classificada como sendo uma open innovation. A elaboração de projetos de captação de recursos para que as empresas do APL possam contratar pesquisa de mercado e, também, para fomentar a participação das empresas em feiras de tecnologia e na busca de novos mercados merece ênfase neste estudo. Todavia o baixo índice de confiança relacionada à inovação faz com que a eficácia das ações seja baixa ou, até mesmo, nula. Ainda nesta análise do contexto interno da open innovation, o APL analisado apresenta diversas intencionalidades, destacando-se: a) elaboração constante de projetos para captação de recursos para o APL; b) tornar mais eficazes as políticas públicas que impactam o APL; c) manter constantemente um funcionário disponível para o gerenciamento do APL; d) promover a integração e cooperação entre 
os atores, para ações voltadas ao desenvolvimento de novos mercados; e e) permitir a análise e o entendimento da realidade econômica e social e, com isso, propor soluções mais eficazes.

Diante do contexto externo, o APL extrapola o conceito de rede ou de cadeia produtiva, porque possui um modelo de governança constituído por empresas públicas e privadas, instituições de ensino, associação comercial, centros de pesquisa e fomentos ao desenvolvimento e representações de classes. Fazer parte do APL amplia a rede de contato das empresas, conforme explica um membro da Associação Comercial, e permite que as empresas do APL possam criar relações de mercado com outras empresas. Um dos coordenadores confirma que fazer parte do arranjo produtivo amplia a rede de contatos das empresas, principalmente na dimensão dos laços fracos (GRANOVETTER, 1983; 1985), no entanto, isso nem sempre converte em faturamento e ganhos financeiros, e muito menos em inovação.

\section{CONSIDERAÇÕES FINAIS}

O presente artigo analisou o processo de constituição da Governança Colaborativa de um APL, do setor metal mecânico, localizado na Região Noroeste do Rio Grande do Sul. A pesquisa sustentou a tese de que o modelo de Governança Colaborativa é fundamental para que o APL se constitua em um ecossistema de inovação aberta. Foram entrevistados diversos atores participantes do processo, que possuem representação da gestão do APL.

Um dos aspectos da análise buscou identificar como ocorrem as etapas de construção da colaboração entre os diversos atores que integram o modelo de governança, analisando as dimensões da comunicação "face to face", da construção da confiança, do compromisso com o processo e visão compartilhada. Percebeu-se que o diálogo existe, e todos os membros da gestão do APL demonstraram que possuem liberdade de expor os seus pontos de vista; mesmo que a busca do consenso tenha sido considerada difícil, com o passar do tempo, houve evolução no diálogo e na colaboração para a construção de projetos de repercussão coletiva. Os resultados apontaram que existe confiança na formulação de estratégias genéricas, porém, já no compartilhamento de informações sobre as estratégias específicas, como no caso da inovação aberta, os atores revelaram que o nível de confiança é baixo.

O compromisso com a implementação das etapas do processo do APL analisado demonstrou que o grupo possui elevado nível de comprometimento e de visão de futuro compartilhada. No período em que houve uma retração dos repasses de recursos financeiros para todos os APLS do Estado, mesmo com esta dificuldade, a Governança Local deste APL decidiu levar adiante o projeto e buscar alternativas para sua consecução.

Na etapa de construção da governança colaborativa, outro ponto obteve destaque; o grupo decidiu elaborar um projeto e captar recursos para a contratação de uma pesquisa de mercado, para o desenvolvimento de novos mercados. Esta pesquisa norteou as estratégias das pequenas, médias e grandes empresas e foi além: os resultados da pesquisa foram apresentados para os governos locais, estaduais e federais. Com esta ação colaborativa, o grupo conseguiu influenciar nas políticas públicas em nível federal para o setor.

No que concerne à análise do conteúdo da inovação, percebe-se que o modelo de governança colaborativa ainda não é capaz de fazer com que as empresas compartilhem informação referente à inovação, dificultando a classificação do APL como um ecossistema de inovação. A inovação ocorre pelo viés da adaptação ao mercado, ou seja, pela inovação incremental, e não 
processos disruptivos. Outro fator que merece destaque é o fato de que as grandes empresas estão dispostas a cooperarem no que se refere à organização de projetos, feiras e viagens técnicas, mas, no que se refere à inovação, não foi possível observar colaboração entre as empresas. Outro fator relevante, no processo de governança colaborativa, é o fato de que as pequenas e médias empresas são mais atuantes que as empresas-âncoras no dia a dia na gestão do APL. Também merece destaque a confiança que está relacionada com a relação entre os atores, e não entre as empresas.

Infere-se que existe um modelo de Governança Colaborativa no APL pesquisado, consolidado na comunicação "face to face", compromisso com o processo e visão compartilhada. Na dimensão de confiança, já ocorreram avanços positivos, mas esta é uma etapa que sempre estará em processo de consolidação. A fragilidade no quesito "inovação aberta" dificultou a afirmação de que neste APL existe um ecossistema de inovação constituído.

Para estudos futuros, recomenda-se a ampliação da amostra para que seja possível analisar e comparar a governança de diversos arranjos produtivos. Outros pontos de destaque que poderão nortear novos estudos são: a) como ocorrem as diversas relações entre os stakeholders no processo de governança colaborativa; b) o papel e a influência da liderança no processo decisório no APL e c) o nível de comprometimento dos diversos atores.

\section{REFERÊNCIAS}

ADNER, R. Match your innovation strategy to your innovation ecosystem. Harvard Business Review, v. 84, n. 4, p. 1-11, 2006.

ADNER, R.; KAPOOR, R. Value creation in innovation ecosystems: how the structure of technological interdependence affects firm performance in new technology generations. Strategic Management Journal, v. 31, n. 3, p. 306-33, 2010.

AGRANOFF, R. Managing collaborative performance: changing the Boundaries of the State? Public Performance \& Management Review, v. 29, n. 1, p. 18-45, 2005.

AMORIM, M. A.; MOREIRA, M. V. C.; IPIRANGA, A. S. R. A construção de uma metodologia de atuação nos Arranjos Produtivos Locais (APLs) no estado do Ceará: um enfoque na formação e fortalecimento do capital social e da governança. Interações - Revista Internacional de Desenvolvimento Local, Campo Grande, MS, v. 6, n. 9, p. 25-34, set. 2004.

ANSELL, C. Collaborative governance. In: LEVI-FAUR, D. The Oxford handbook of governance. Oxford, UK: Oxford University Pres, 2012.

ANSELL, C.; GASH, A. Collaborative governance in theory and practice. Journal of Public Administration Research and Theory, v. 18, n. 4, p. 543-71, 2007.

ANSELL, C.; TORFING, J. How does collaborative governance scale? Policy \& Politics, v. 43, n. 3, p. 315-29, 2015.

ARANHA, J. A. S. Mecanismos de geração de empreendimentos inovadores: mudanças na organização e na dinâmica dos ambientes e o surgimento de novos atores. Brasília: Anprotec, 2016.

AUDY, J. A inovação, o desenvolvimento e o papel da Universidade. Estudos Avançados, São Paulo, v. 31, n. 90, p. 75-87, maio/ago. 2017. 
AUDY, J.; PIQUÉ, J. Dos parques cientificos e tecnológicos aos ecossistemas de inovação: desenvolvimento social e econômico na sociedade do conhecimento. Brasília: ANPROTEC, 2016.

BALLON, P.; PIERSON J.; DELAERA S. Open innovation platforms for broadband services: Benchmarking European Practices. Proceedings of 16th European Regional Conference, Porto, Portugal, September 4-6, 2005.

BENGTSSON, M.; KOCK, S. "Coopetition" in business networks - to cooperate and compete simultaneously. Industrial Marketing Management, v. 29, p. 411-26, 2000.

BODIN, O. Collaborative environmental governance: achieving collective action in social-ecological systems. Science, v. 357, n. 6352, p. 659-68, 2017.

BOEIRA, L.; BORBA, J. Os fundamentos teóricos do capital social. Ambiente \& Sociedade, Campinas, SP, v. 9, n. 1, p. 187-93, jan./jun. 2006.

BURREL, G.; MORGAN, G. Sociological paradigms and organizational analysis. London: Heinemann Educational Book, 1979.

FISHER, B. B.; ZAYAS, J. M. Towards a taxonomy of firms engaged in international R\&D networks: an evaluation of the Spanish participation in Eureka. Journal of Technology Management \& Innovation, v. 7, n. 3, p. 121-34, 2012.

BRASIL. Ministério do Desenvolvimento, Indústria e Comércio Exterior. Relatórios APLS U.E. [s.d.]. Disponível em: http://www.desenvolvimento.gov.br/inovacaoapls2010.br.ue/default/index/clustersue. Acesso em: 24 nov. 2018.

CASSIOLATO, J. E.; LASTRES, H. M. M.; MACIEL, M. L. Pequena empresa: cooperação e desenvolvimento local. Rio de Janeiro: Relume Dumará, 2003.

CHESBROUGH, H. W. The era of open innovation. Managing Innovation and Change, v. 127, n. 3, p. 3441, 2006.

CHESBROUGH, H. W.; VANHAVERBEKE, W.; WEST, J. Open innovation researching - a new paradigm. Oxford: Oxford University Press, 2008.

COASE, R. H. The Nature of the Firm. The London School of Economics and Political Science, v. 4, n. 16, p. 386-405, 1937.

DAHLANDER, L.; GANN, D. M. How open is innovation? Research Policy, n. 39, p. 699-709, 2010.

DASÍ, J. F. Gobernanza territorial para el desarrollo sostenible: estado de la cuestión y agenda. BAGE, n. 46, 2008.

DUTILLEUL, B.; BIRRER, F. A. J.; MENSINK, W. Unpacking european living labs: abalysing innovation's social dimensions. European Journal of Public Policy, v. 4, n. 1, p. 60-85, jul. 2010.

DYER, J.; NOBEOKA, K. Creating and managing a high-performance knowledge-sharing network: the Toyota case. Strategic Management Journal, v. 21, n. 3, p. 345-67, 2000.

EDELENBOS, J. Institutional implications of interactive governance: insights from Dutch practice. Governance, v. 18, n. 1, p. 111-34, 2005. 
EMERSON, K.; NABATCHI, T.; BALOGH, S. An integrative framework for collaborative governance. Journal of Public Administration Research and Theory, v. 22, n. 1, p. 1-29, 2012.

FERRÃO, J. Governança e ordenamento do território: reflexões para uma governança territorial eficiente, justa e democrática. Prospectiva e Planejamento, v. 17, p. 129-39, 2010.

FILIPPIM, E.; ROSSETO, A. (Org.). Políticas públicas, federalismo e redes de articulação para o desenvolvimento. Joaçaba, SC: UNOESC, 2008.

GASSMANN, O. Opening up the innovation process: towards an agenda. R\&D Management, v. 36, n. 3, p. 223-8, 2006.

GRANOVETTER, M. S. Getting a job: a study of contacts and careers. 2. ed. Chicago: The University of Chicago Press, 1985.

GRANOVETTER, M. S. The strength of weak ties: a network theory revisited. Sociological Theory, v. 1, p. 201-33, 1983.

GRAY B. Collaborating: finding common ground for multi-party problems. San Francisco, CA: Jossey-Bass, 1989.

GUERRA, R. M. A.; TONDOLO, V. A. G.; CAMARGO, M. E. O que (ainda) podemos aprender sobre capacidades dinâmicas. Revista Ibero-Americana de Estratégia, São Paulo, v. 15, n. 1, p. 44-64, jan./mar. 2016.

HABERMAS, J. Teoría de la acción comunicativa. Madri: Tauros, 1987.

HUIZINGH, E. K. R. E. Open innovation: state of the art and future perspectives. Technovation, v. 31, n. 1, p. 2-9, 2010.

IANSISTI, M.; LEVIEN, R. Strategy as ecology. Harvard Business Review, v. 82, n. 3, p. 1-11, 2004.

IKENAMI, R. K. A abordagem "ecossistema" em teoria organizacional: fundamentos e contribuições. 2016. 153 p. Dissertação (Mestrado em Ciências) - Escola Politécnica da Universidade de São Paulo, São Paulo, 2016.

INNES, J. E.; BOOHER, D. E. Consensus building and complex adaptive systems: a framework for evaluating collaborative planning. Journal of the American Planning Association, v. 65, n. 4, p. 412-23, 1999.

JENSEN, M.; MECKLING, W. Theory of the firm: managerial behavior, agency costs and ownership structure. Journal of Financial Economics, v. 3, n. 4, p. 305-60, 1976.

KAUFMAN, D. A força dos "laços fracos" de Mark Granovetter no ambiente do ciberespaço. Galáxia, São Paulo, n. 23, p. 207-18, jun. 2012.

KOOIMAN, J. (Ed.). Modern governance: new government-society interactions. [S.I.]: Sage, 1993.

LANE, P. J.; KOKA, B. R.; PATHAK, S. The reification of absorptive capacity: a critical review and rejuvenation of the construct. Academy of Management Review, v. 31, n. 4, p. 833-63, 2006.

LIMA, L. Os efeitos dos laços fracos sobre os laços fortes: uma relação entre associativismo e indicadores de capital social. Revista Três Pontos, Belo Horizonte, v. 2, n. 2, p. 47-54, 2016.

LUBIK, S.; GARNSEY, E.; MINSHALL, T.; PLATTS, K. Value creation from the innovation environment: partnership strategies in university spin-outs. R\&D Management, v. 43, n. 2, p. 136-50, 2013. 
LUNDVALL, B. National systems of innovation: towards a theory of innovation and interactive learning. London: Pinter, 1992. p. 1-19.

MALMBERG, A.; MASKELL, P. The elusive concept of localization economies: towards a knowledge-based theory of spatial clustering. Environment and Planning, v. 34, n. 3, p. 429-50, 2001.

MAZZUCO, E.; TEIXEIRA, C. Living labs: intermediários da inovação. Revista Eletrônica do Alto do Vale do Itajaí, Ibirama, SC, v. 6, n. 9, p. 87-97, jul. 2017.

MOORE, J. The death of competition: leadership and strategy in the age of business ecosystems. Nova York: Harper Business, 1993.

NONAKA, I.; TAKEUCHI, H. Criação do conhecimento na empresa: como as empresas geram a dinâmica da inovação. Rio de Janeiro: Campus, 1997.

OSTROM, E. Governing the commons: the evolution of institutions for collective action. New York: Cambridge University Press, 1990.

PETTIGREW, A.; FERLIE, E.; McKEE, L. Shaping strategic change: the case of the NHS in the 1980s. Public Money \& Management, v. 12, n. 3, p. 27-31, jul. 1992.

POWELL, W. Learning from collaboration. knowledge and networks in the biotechnology and pharmaceutical industries. California Management Review, v. 40, n. 3, 1998.

PUGA, F. P. Alternativas de apoio a MPMEs localizadas em arranjos produtivos locais Rio de Janeiro: BNDES, 2003. (Texto para discussão n. 99).

RUSSEL, M. G. et al. Transforming innovation ecosystems through shared vision and network orchestration. In: TRIPLE HELIX INTERNATIONAL CONFERENCE, 9., 2011, Stanford. Anais [...]. Stanford: Stanford University, H-STAR Institute Center for Innovation and Communication, 2011. p. 1-21.

SILVA, S.; BIGNETTI, L. P. A inovação social e a dinâmica de inovação aberta na Rede Brasileira de Living Labs. In: ENCONTRO DA ASSOCIAÇÃO NACIONAL DE PÓS-GRADUAÇÃO E PESQUISA EM ADMINISTRAÇÃO, 36., 2012, Rio de Janeiro. Anais [...]. Rio de Janeiro, 2012.

SUZIGAN, W.; GARCIA, R.; FURTADO, J. Estruturas de governança em arranjos ou sistemas locais de produção. Gestão e Produção, São Carlos, SP, v. 14, n. 2, p. 425-39, maio/ago. 2007.

TENÓRIO, F. G. Gestão social e gestão estratégica: experiências em desenvolvimento territorial. Rio de Janeiro: Editora FGV, 2013.

TIDD, J.; BESSANT, J.; PAVITT, K. Gestão da inovação. 3. ed. Porto Alegre: Bookman, 2015.

VANGEN, S.; HUXHAM, C. Enacting leadership for collaborative advantage: dilemmas of ideology and pragmatism in the activities of partnership managers. British Journal of Management, v. 14, n. 1, p. 6176, 2003.

WILLIAMSON, O. E. The economic institutions of capitalism. New York: Free Press, 1996.

YIN, R. K. Estudo de caso: planejamento e métodos. São Paulo: Bookman, 2001. 


\section{Sobre os autores:}

Cátia Raquel Felden Bartz: Doutoranda e mestre em Desenvolvimento Regional pela Universidade Regional do Noroeste do Estado do Rio Grande do Sul (UNIJUÍ). Professora da Faculdade Horizontina (FAHOR), nos Cursos de Ciências Econômicas, Engenharia de Produção e Engenharia Mecânica. E-mail: catiafelden@hotmail.com, Orcid: http://orcid.org/0000-0002-6008-1565

Jéssica Casali Turcato: Mestranda em Desenvolvimento Regional pela Universidade Regional do Noroeste do Estado do Rio Grande do Sul (UNIJUÍ); bolsista CAPES PPGDES/ UNIJUÍ. Bacharel em Administração pela UNIJUÍ. E-mail: jehturcato@hotmail.com, Orcid: http://orcid.org/0000-0003-1982-6868

Jorge Oneide Sausen: Pós-doutor em Administração pela Escola Brasileira de Administração Pública e de Empresas (EBAPE), Fundação Getúlio Vargas (FGV-RJ). Doutor em Engenharia da Produção pela Universidade Federal de Santa Catarina (UFSC). Mestre em Administração pela Universidade Federal do Rio Grande do Sul (UFRGS). Professor do Programa de Pós-Graduação em Desenvolvimento Regional da Universidade Regional do Noroeste do Estado do Rio Grande do Sul (UNIJUÍ). E-mail: josausen@unijui.edu.br, Orcid: http://orcid.org/0000-0003-3684-1410

Daniel Knebel Baggio: Doutor e mestre em Contabilidade e Finanças pela Universidad de Zaragoza, revalidado pela Universidade de São Paulo (USP), em Controladoria e Contabilidade. Graduado em Administração pela Universidade Regional do Noroeste do Estado do Rio Grande do Sul (UNIJUÍ). Professor do Programa de Pós-Graduação em Desenvolvimento Regional da UNIJUÍ e do Programa de Pós-Graduação em Gestão Estratégica de Organizações da Universidade Regional Integrada (URI). Investigador pela Universidade de Zaragoza, integrando o Grupo de Investigación en Economia Financiera (GIECOFIN); pela UNIJUÍ, integrando o Grupo de Pesquisa em Competitividade e Gestão Estratégica para o Desenvolvimento (GPCOM); e pela URI, integrando o Grupo de Pesquisa de Métodos Aplicados à Gestão Organizacional (MAGO). E-mail: baggiod@unijui.edu.br, Orcid: http://orcid.org/0000-0002-6167-2682 